A publication of the Muma College of Business | University of South Florida

Volume 3

Number 19

31 DEC 2018

ZAMA DLAMINI, LINDA MALINGA, JACKIE PHAHLAMOHLAKA, SIPHO NGOBENI

\title{
TRANSFORMING THE SIYABUSWA COMMUNITY CENTRE INTO A SMART CENTRE ${ }^{1}$
}

Dr. Jackie Phahlamohlaka reflected on what he would propose to the board regarding the transformation of the existing Siyabuswa Educational Improvement and Development Trust (SEIDET) community centre to a smart community centre. As the Competency Area Manager at the Council for Scientific and Industrial Research (CSIR) in South Africa, the founder of SEIDET and the chairman of its Board of Trustees, he had for over twenty-four years led socio-economic development efforts and ICT related research linked to SEIDET (SEIDET, 2014). These programmes ranged from high school supplementary tutorials on mathematics and science to adult and computer literacy training of the broader community in the Siyabuswa area of Mpumalanga Province, Republic of South Africa.

The concept of a smart centre describes a facility that optimally uses advanced technologies and innovations as well as streamlined processes in order to address challenges faced by communities. Jackie envisioned the establishment of a Digital Village as the foundation for the SEIDET Smart Community Centre in Siyabuswa. This Digital Village would consist of a substantial expansion of the present SEIDET offering. The educational offering at the envisaged smart centre would be drastically scaled up in relation to the present offering, and there would be a big drive to promote entrepreneurship in the community of Siyabuswa. These undertakings were being considered in order to contribute to the socioeconomic development of the area of Siyabuswa. This was indeed a challenging task for Dr.

Phahlamohlaka to get SEIDET to achieve its potential and to address some of the big challenges in the community of Siyabuswa.

For a community development agency such as SEIDET to achieve its objective of morphing the present community centre into a smart community centre, there were some key questions that Jackie needed to address. These questions were: (1) How could SEIDET leverage or create affordable cyber network infrastructure in the envisaged smart centre? (2) How could the smart centre assist the local community and individuals in the community to be enabled to participate in local economic development? (3) How could SEIDET get the local government administration, traditional leaders and the local community to buy-in to this smart centre development project in order to ensure its sustainability?

${ }^{1}$ Copyright (C) 2018, Zama Dlamini, Linda Malinga, Jackie Phahlamohlaka and Sipho Ngobeni. This case was prepared for the purpose of class discussion. Names and some information have been disguised. This case is published under a Creative Commons BY-NC license and originally appeared as a chapter in Transforming Society Using ICT: Contemporary Discussion Cases from Africa. Permission is granted to copy and distribute this case for non-commercial purposes, in both printed and electronic formats. 


\section{Background on SEIDET}

SEIDET being a development agency and a non-profit organization was launched in 1992 and was founded in the Siyabuswa community, within Dr. JS Moroka Municipality, in the Mpumalanga Province of the Republic of South Africa. The core remit of SEIDET was developmental work within the Siyabuswa community. Their initial offering consisted of supplementary classes for high school students in science and mathematics, as well as computer literacy training for the community, and several other socio-economic development programmes. The directors of SEIDET had a wealth of experience in the implementation of development projects in Siyabuswa gathered during SEIDET's twenty four years of existence.

The SEIDET Campus consisted of two natural science laboratories (one each for physics and chemistry), two computer laboratories, several classrooms and an administrative block. The campus was located on hectares of land, which had been donated to the project by the King of the Ndebele people. Various funders contributed to the construction of the SEIDET Campus (see Exhibit 1 and Exhibit 2 for pictures of the SEIDET Campus).

Various projects were hosted at the two computer laboratories. These projects included educational and business oriented initiatives. The goal of these projects was to involve various stakeholders from the public and private sectors as well as the general community in educational and economic development programmes. SEIDET's rich history and contribution to human capital development, especially in science and technology education, was well documented; collaborations with academic institutions resulted in several qualifications being awarded and conference proceedings, journal publications and a book being published. It was estimated from the long history of SEIDET that more than 10,000 learners benefited from SEIDET educational interventions.

A number of ICT related initiatives took place at the SEIDET Community Centre involving various stakeholders such as the South African government, the Mpumalanga Provincial administration, several local municipalities, private companies, academic and research institutions (such as the University of Pretoria (UP), the University of South Africa and the CSIR).

The ICT initiatives at the SEIDET Community Centre, which were run in collaboration with UP and CSIR (the two major stakeholders in the history of SEIDET), included the e-entrepreneurial training and e-skills programmes, cybersecurity awareness training and a project on community development workers called the Village Operators project.

SEIDET had a particularly close working relationship with the UP (see Exhibit 1), which had proven to be fruitful to both organizations. UP provided support to SEIDET, and SEIDET provided a research site to the university.

Through these types of collaborations, Jackie and his team wanted to explore how best to leverage off the type of work being undertaken at the SEIDET Community Centre in order to aid its transformation into a smart digital village. The team pondered: could the three initiatives discussed above be better managed within the concept of a smart city?

\section{Conception of the Smart Community Centre for Siyabuswa}

The smart community centre concept was extrapolated from the concept of a smart city. The concept of a smart city was popular across the world and at the centre of attention of global industrial and governments sectors. What was described as a smart city is captured by the following quotation: "The vision of a smart city is the urban centre of the future, made safe, environmentally green, and efficient because all 
structures - whether power, water, transportation, etc. are designed, constructed, and maintained making use of advanced, integrated materials, sensors, electronics, and networks which are interfaced with computerized systems.” (Hall, 2000).

Inspired by the above mentioned definition, Jackie and his team proposed a service-based smart community centre model (see Exhibit 2) that could be used to transform the SEIDET Community Centre into a smart community centre. They identified the common components of a smart community centre as people, technology and governance. These were regarded as the drivers to achieve a smart community centre.

The people aspect of a community centre was defined as a group of individuals and organisations that worked together to leverage off Information Technology (IT) in the creation of economic, cultural and social value. Smart community centre members included individuals as well as educational, governmental and business organisations. In other words, a smart community was a system where people and organisations used IT to enhance the way that they conducted their everyday business. This enhancement would lead to advantages, such as, new revenue streams or attaining new knowledge that could be used to improve the efficiency of business functions. These smart communities have also existed in the virtual space, such as the SecondLife or a hybrid consisting of physical and virtual space, such as, USA's Silicon Valley.

On the SecondLife platform, people leveraged off the internet to perform business transactions, present lectures and even host social gatherings. In both domains, physical and virtual members of the community built relationships with each other for specific purposes such as collaborating, learning, information and resource sharing. Simple provision of IT hardware and network connectivity to a community did not necessarily make the domain a smart community. The individuals and organisations within the community would have to be educated and trained to make the applications more accessible and useful to them. It was only when the members of the community used IT capabilities to produce new value additions for improving their lives that a domain could be classified as a smart community.

The management of Dr. JS Moroka Local Municipality had agreed to be part of a strategic partnership between UNISA and SEIDET to collaborate on the ICT4D project to provide unemployed youths with ICT skills that would enable them to generate income by selling such skills to the Municipality and the local community. This strategic partnership with a municipality in an area in which SEIDET operated was likely to contribute positively towards the transformation of the centre into a smart community centre.

It was clear that the environment described above was ripe and conducive for the currently existing SEIDET community centre to be transformed into a smart state-of-the art community centre, which when operated optimally with streamlined processes could address the challenges faced by the community of Siyabuswa.

\section{BB4LL Affordable Cyber Network Architecture}

Affordable network infrastructure, especially broadband connectivity, is one of the most important catalysts for economic and social inclusion, especially in rural communities. BB4ALL, short for Broadband for All, was a collaboration effort led by the Meraka Institute of the CSIR. This initiative targeted bridging the digital divide and bringing the social and economic benefits offered by broadband connectivity to rural communities in South Africa in a cost-effective and sustainable fashion. One approach that made this possible was the sharing of connectivity through utilisation of "mesh" network 
principles and equipment. These networks created and expanded coverage within local communities negating the need for expensive radio equipment and high maintenance radio towers (See Exhibit 3 for the network architecture of BB4ALL).

In the BB4ALL network, mesh networks were linked to each other creating a "backhaul mesh" network. This backhaul mesh was also connected to an Internet Protocol (IP) backbone that provided IP services and internet access (Meraka, 2009). This type of architecture ensured redundancy for user connectivity. Jackie wondered if the envisaged SEIDET Smart Community Centre could leverage off the existing cyber network to enable a digital pipe through which the Smart Community Centre users could connect and access services.

In addition, the CSIR, in collaboration with SEIDET, identified individuals within the local community of Siyabuswa, called Village Operators (VO). The VOs were a category of community development workers. The VOs were skilled and trained entrepreneurship, and their role was to take responsibility for operating, promoting and expanding the BB4ALL service offering. SEIDET facilitated the recruitment of VOs via schools and the Mpumalanga Department of Education. SEIDET was regarded as a significant stakeholder and key contributor to the BB4ALL initiative. The VOs went through entrepreneurial and business mentoring, personal development and training on the maintenance, operation and support of the BB4ALL network infrastructure.

\section{Details of the Smart Community Centre Model for Siyabuswa}

Four main services of the smart community centre were identified: Smart Infrastructure, Smart Users, Smart Applications and Smart Governance. Smart users would be given the skills and the capacity to deliver knowledge-based services. The training was conducted on: network and user applications, network access devices and infrastructure, entrepreneurship, and basic computer skills. Smart Infrastructure included ICT and network-based equipment and software. The BB4ALL network is an example of smart infrastructure. Smart Applications services referred to the application of specific services, i.e. they would be developed as per the application requirements. Smart Governance services referred to the policies, rules and regulations services, not ignoring management, of the relationship with various stakeholders, such as the traditional leaders, who were commonly found in the rural areas of South Africa. Smart Governance also specified the interaction between the various smart services.

Four layers were defined by Jackie and his team in the smart community centre model. Exhibit 2 shows the architecture of the model together with its components. These were components that provided different services at different levels in a resource management process. These layers are as follows:

- Access Layer: This was the user layer responsible for access to the system. The main role of this layer was to enhance sharing amongst the users and to supply information about resources and available services between the users and the routing layer.

- Routing Layer: This layer was responsible for the routing of requests between the entities (users and Central Management System (CMS)) in the system. All data shared by users was interconnected, structured, sorted, processed and routed by this layer, to and from both the access and management layer.

- Management Layer: This layer was responsible for central managing of the resources. It was the layer where all the data (shared services, application, software and others) was stored and managed for efficient utilization, intelligent decision-making, and better service monitoring and ease of access of services. 
- Information Security Layer: This layer cut across all the services of the smart community centre model. It was responsible for ensuring that the information transmitted in each service of the model complied with the three basic principles of information security, that is, confidentiality, integrity and availability (CIA), as outlined in the ISO 27001.

\section{The Decision}

As chairman of the Board of Trustees of SEIDET, Jackie needed to propose to the SEIDET Board how best to transform the SEIDET Community Centre into a smart community centre. This proposal needed to be consistent with achieving SEIDET's strategic objectives, namely designing and delivering innovative, educational and socio-economic development programmes in order to contribute to the development of the Siyabuswa community.

As a senior manager at the CSIR, Jackie approached one of his CSIR teams for assistance when deciding how to proceed. The team in question had previously experimented with the concept of a smart city in their work. Jackie also saw this as an opportunity for the CSIR and SEIDET to continue their collaboration and to raise their level of engagement. He wondered whether the existing BB4ALL could be leveraged off for provision of ubiquitous area coverage for the users of the smart community centre.

The BB4ALL infrastructure, which was developed by the CSIR, had been deployed across a number of schools in the area. The BB4ALL network provided internet access to its users even though at that time the SEIDET Community Centre did not have access to the BB4ALL network or internet. The BB4ALL offered an option of cyber network connectivity for the envisaged smart community centre.

The collaboration between SEIDET and the academic institutions already provided a variety of training and e-skills instruction. Jackie wondered whether these service offerings were sufficient for the envisaged educational offering in the smart community centre. Furthermore, considering the fact that the 'smart' community centre concept was still at its infancy, who could offer training on management and administration of the smart community centre to the personnel and directors of the smart community centre? Would training be provided by the present partners or would it be procured from abroad? If an international service provider was chosen, how would this training be financed-especially given the fact that SEIDET was a non-profit organization?

On the issue of economic participation by the local community, SEIDET, in collaboration with the CSIR, had identified and trained some community development workers on entrepreneurship skills thus producing the earlier described VOs. As already explained, these development workers were mainly trained on the use and maintenance of BB4ALL technology. Should now SEIDET consider the recruitment of completely new VOs or pre-trained and by extension currently available VOs? It was envisioned that the role of the VOs associated with SEIDET would enhance and promote the entrepreneurial activities of the envisaged SEIDET digital village instead of an exclusive focus on the BB4ALL network.

The relationship between SEIDET and the local community had proven to be fruitful during the many years of SEIDET's existence. Many of SEIDET's alumni could be approached and asked to plough back into the community by assisting SEIDET in their new venture of bringing about a smart community 
centre in Siyabuswa. Some of these alumni occupied important positions in the society. For example, some were medical doctors and engineers. SEIDET also had a healthy relationship with the two tiers of government, namely the municipality of Siyabuswa as well as the Mpumalanga Provincial government. The traditional leadership that were involved for many years in SEIDET's projects could also be used as an important resource in the envisaged expansion of SEIDET's offering. For instance the land on which the SEIDET campus was build was given for free to SEIDET by the king of the Ndebele people. So SEIDET had this network that it could leverage in their new venture. This network was critical to SEIDET's model of bringing about the smart community centre in Siyabuswa community.

At the end of the day, the question remained, would this model put together by Dr. Phahlamohlaka be enough to enable the transformation of the SEIDET Community Centre into a smart community centre?

\section{Reference List}

Phahlamohlaka, J. (2008). Community-driven projects: reflections on a success story: a case study of science education and information technology in South Africa. Van Schaik Publishers.

Phahlamohlaka, I. Z. Dlamini, T. Mnisi, T. Mashiane and L. Malinga, (2014). Towards a Smart Community Centre: SEIDET Digital Village, ICT and Society.

CSIR Meraka. (2009). Broadband 4 All ${ }^{T M}$. Retrieved March 28, 2014, from http://www.broadband4all.co.za/

Hall R. (2000, September 28,). The vision of a smart city. $2^{\text {nd }}$ International Life Extension Technology Workshop. Paris, France.

Meraka (2009). Mesh Networks. Retrieved March 28, 2014, from http://www.meshnetworks.com/

SEIDET (2014). SEIDET. Retrieved from http://zotero.org/support/quick_start_guide 


\section{Biographies}

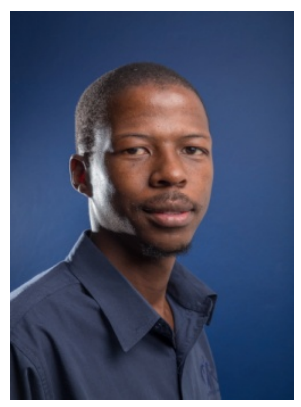

Linda Malinga holds a Bachelor of Honours Degree in Electronic and Electrical Engineering from the University of Pretoria (South Africa). He works for the Council for Scientific and Industrial Research (CSIR) where he is involved in modeling and simulation-based projects supporting Acquisition Decision, specifically for the South African National Defence Force (SANDF).

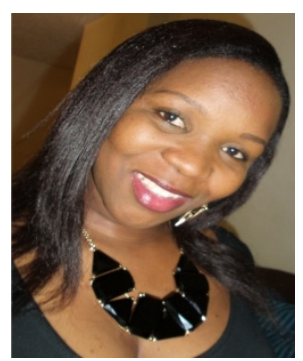

Zama Dlamini studied both her undergraduate and honours in Computer Science, at the University of Zululand, South Africa. She completed her MSc in Digital Forensics with the University of Pretoria; and also works for CSIR-DPSS (Cyber Defence Research Group) as Cybersecurity Specialist and Researcher, since 2008 to date.

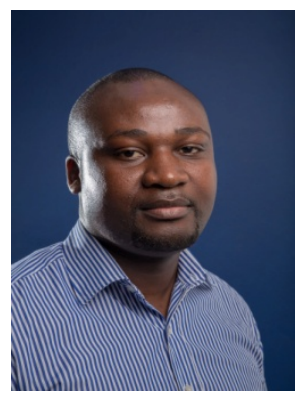

Sipho Ngobeni is the Senior Cyber-Security Researcher at the CSIR and his role entails the development and implementation of information security strategies, policies, standards, processes, procedures and frameworks. He also plays an advisory role towards the design and implementation of IT Infrastructure and Security solutions to clients, ensuring that information assets and technologies are adequately protected.

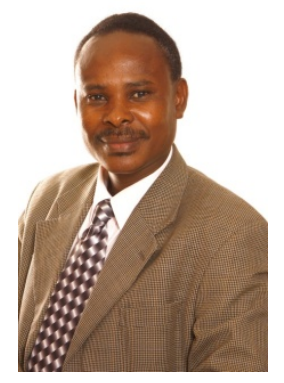

Dr Jackie Phahlamohlaka is the Competency Area Manager at the Council for Scientific and Industrial Research (CSIR), and also the founder of SEIDET and the chairman of its Board of Trustees. He completed the Executive National Security Programme (ENSP) at the South African National Defence College in 2007. His research interests are in ICT and socio-economic development, web-based group support systems, and broadband access and national security. 


\section{Exhibit 1: A Photo of the SEIDET Campus}

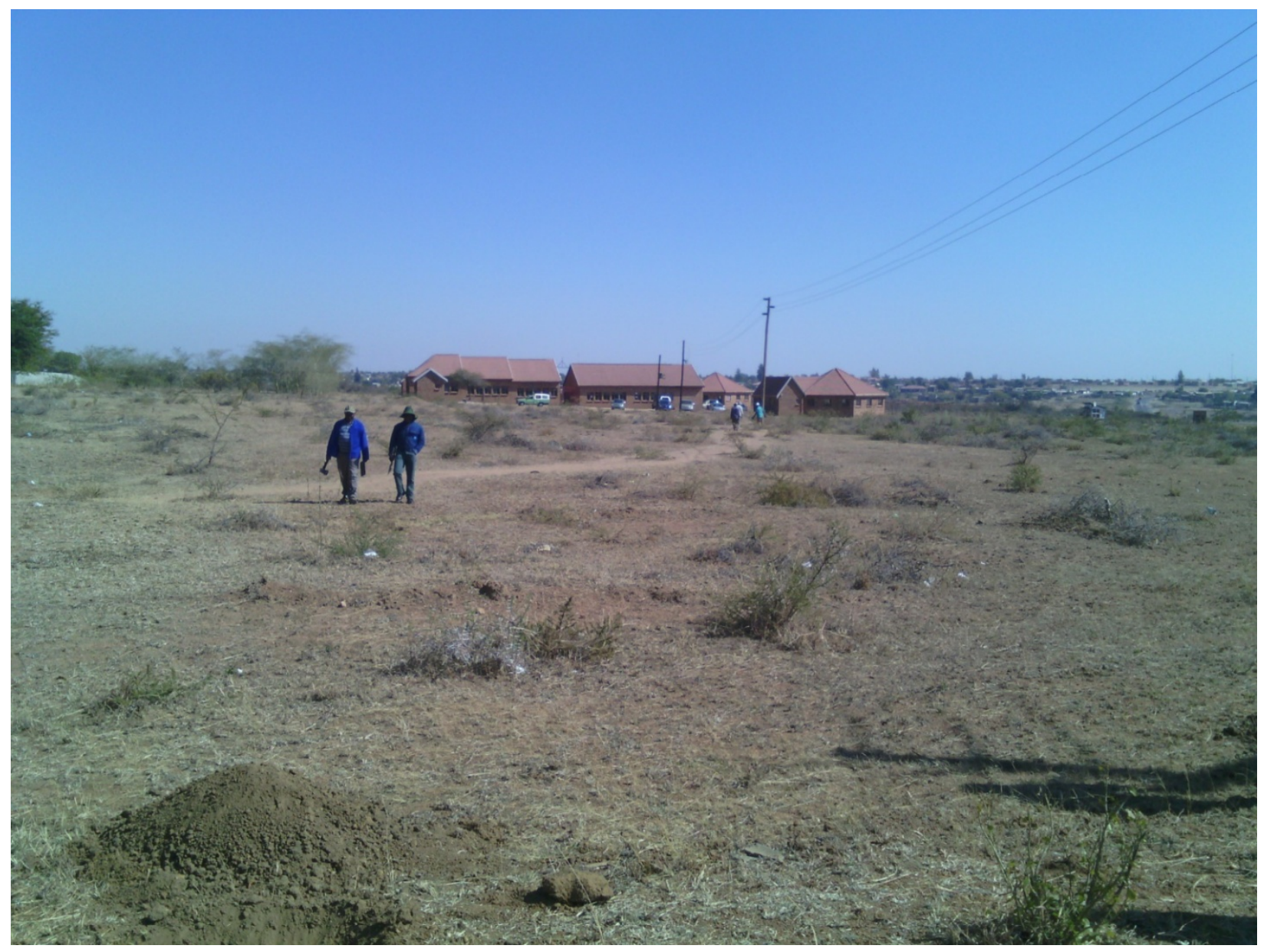




\section{Exhibit 1: A Close up Photo of SEIDET Premises}

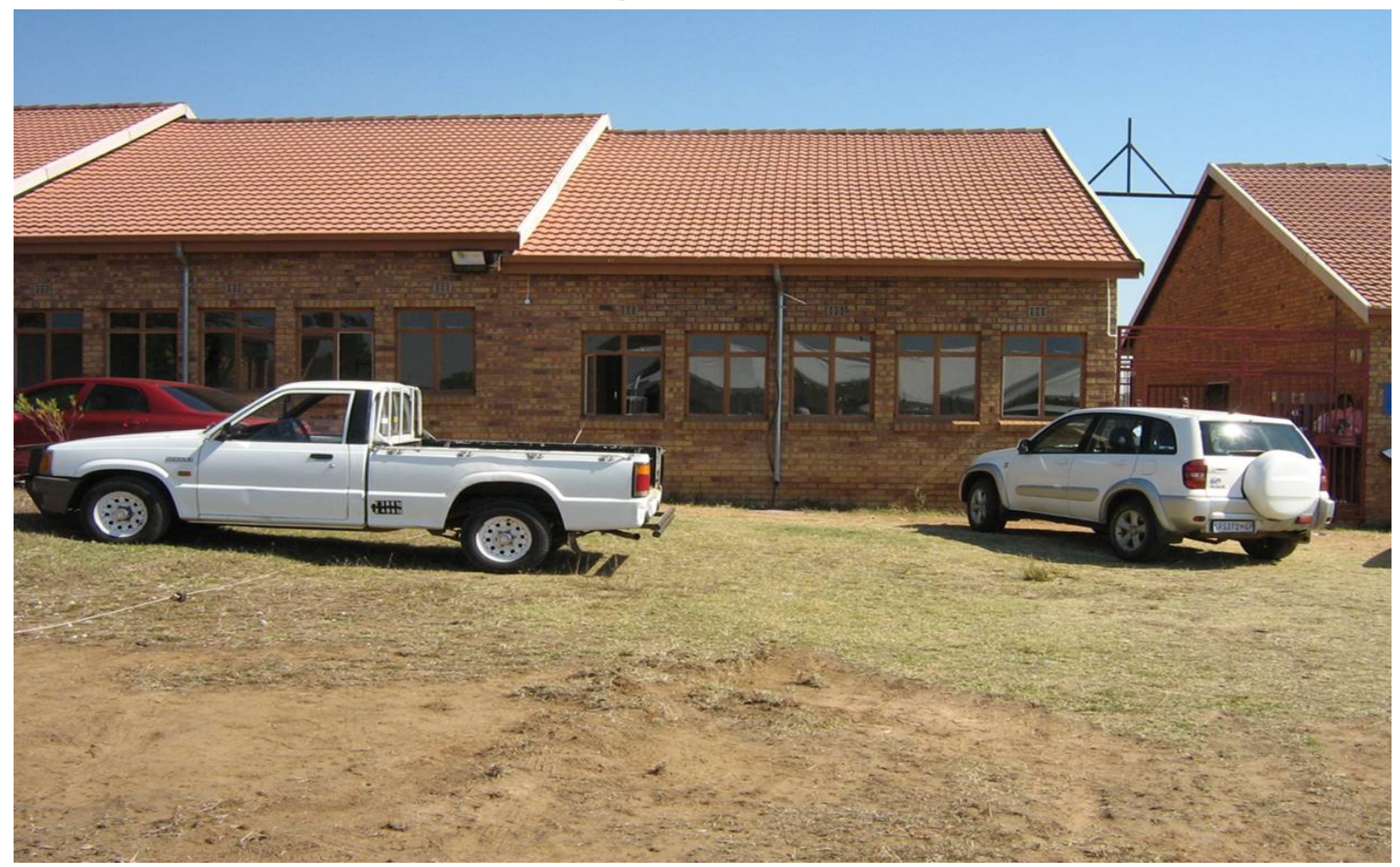


Exhibit 1: University of Pretoria Researchers, with Teachers and Learners at Siyabuswa

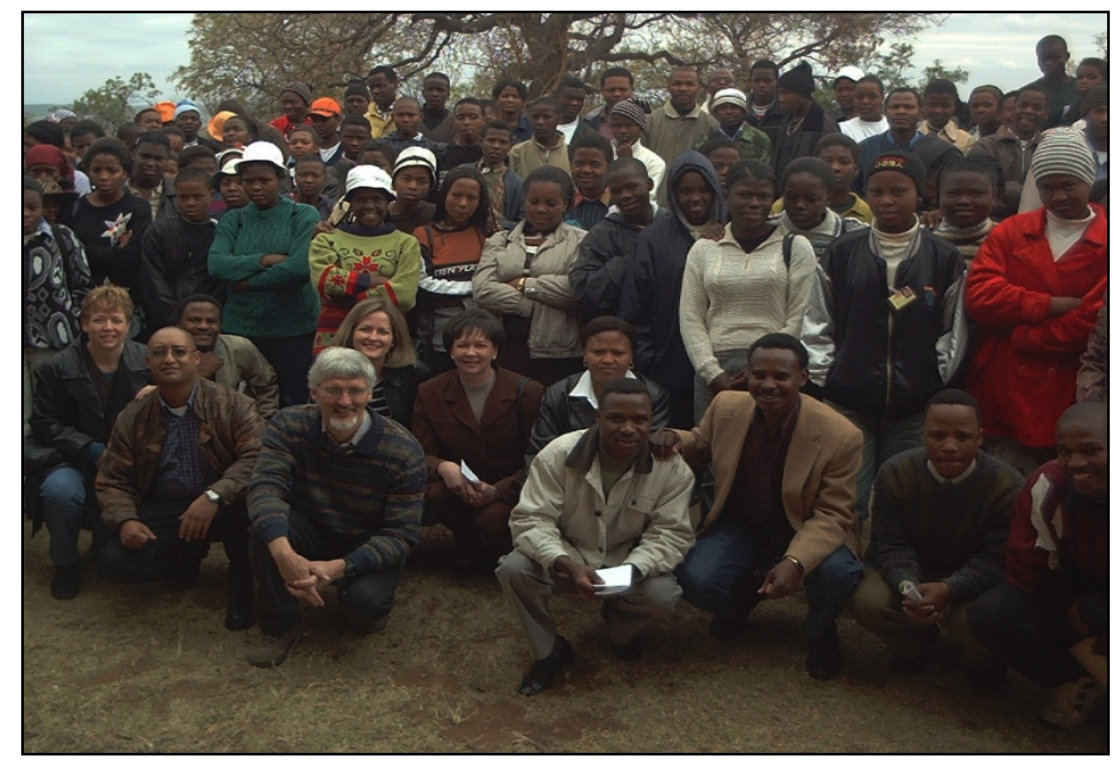

Source: Phahlamohlaka (2008) 
Exhibit 2: Smart Community Centre Model

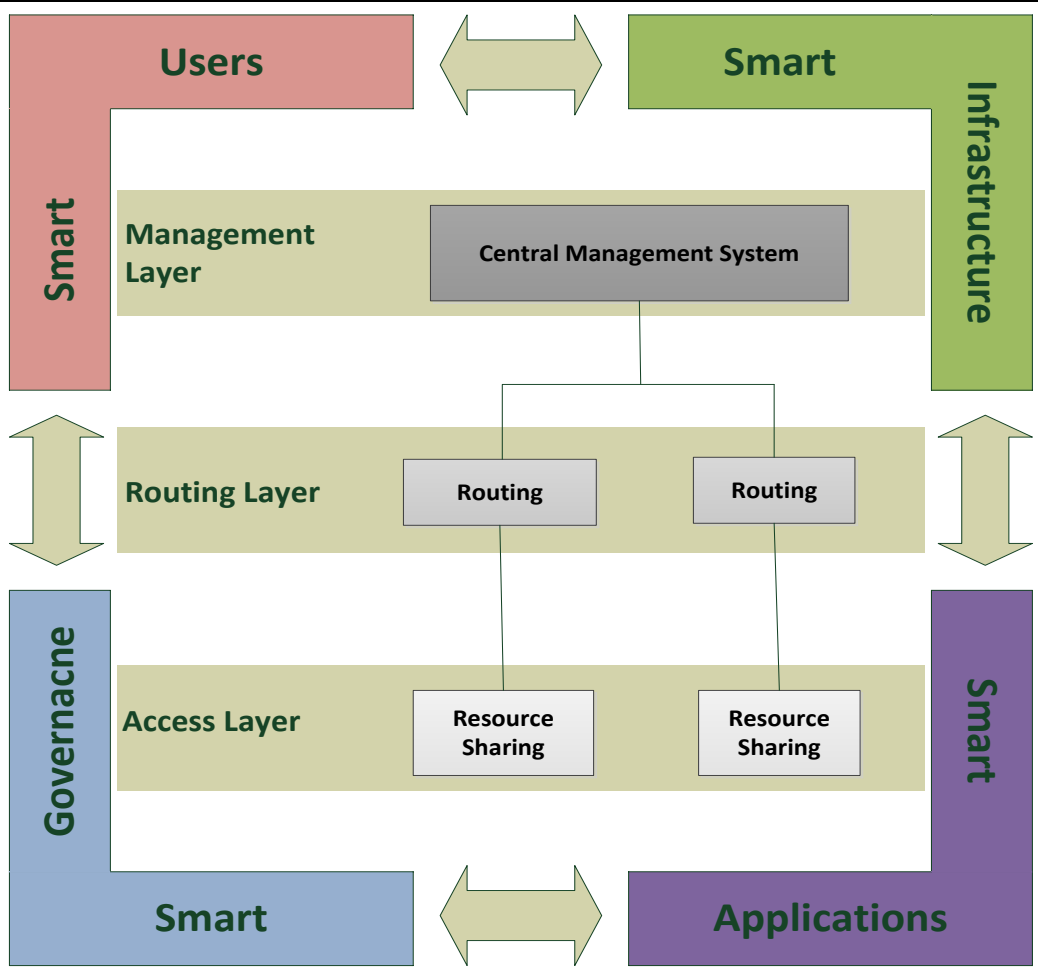

Source: Phahlamohlaka et al (2014) 


\section{Exhibit 3: BB4ALL Network Diagram}

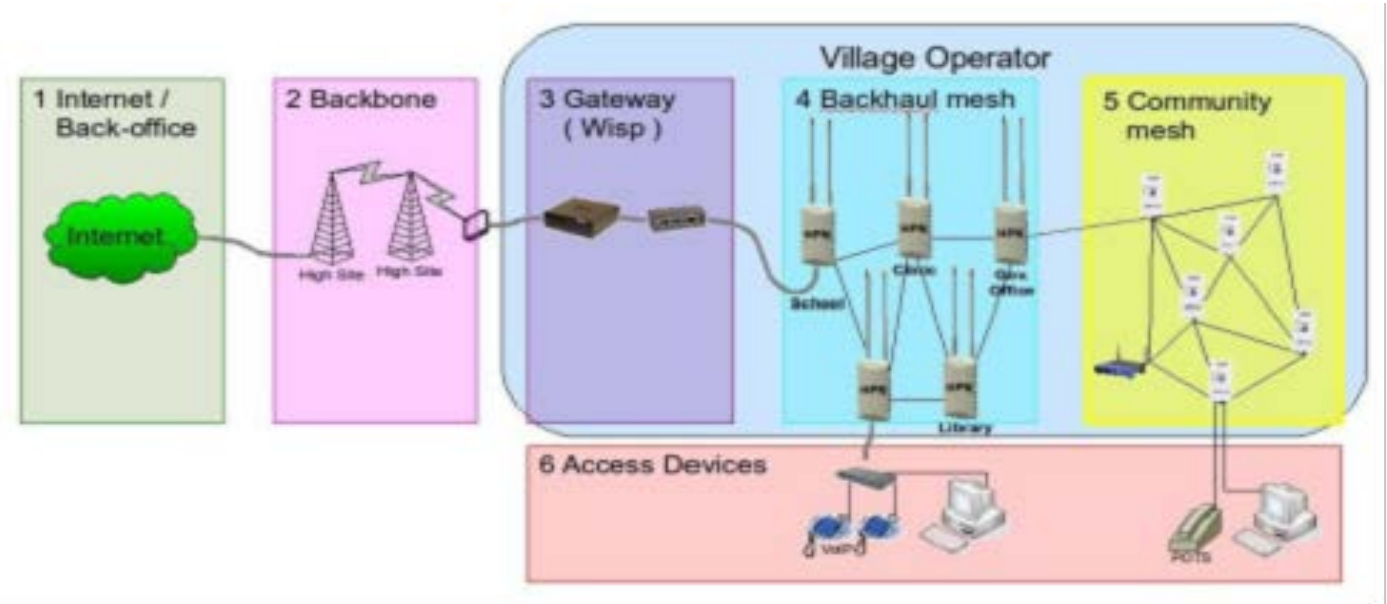

Source: CSIR Meraka (2009) 
Exhibit 4: One of the SEIDET Computer Laboratories

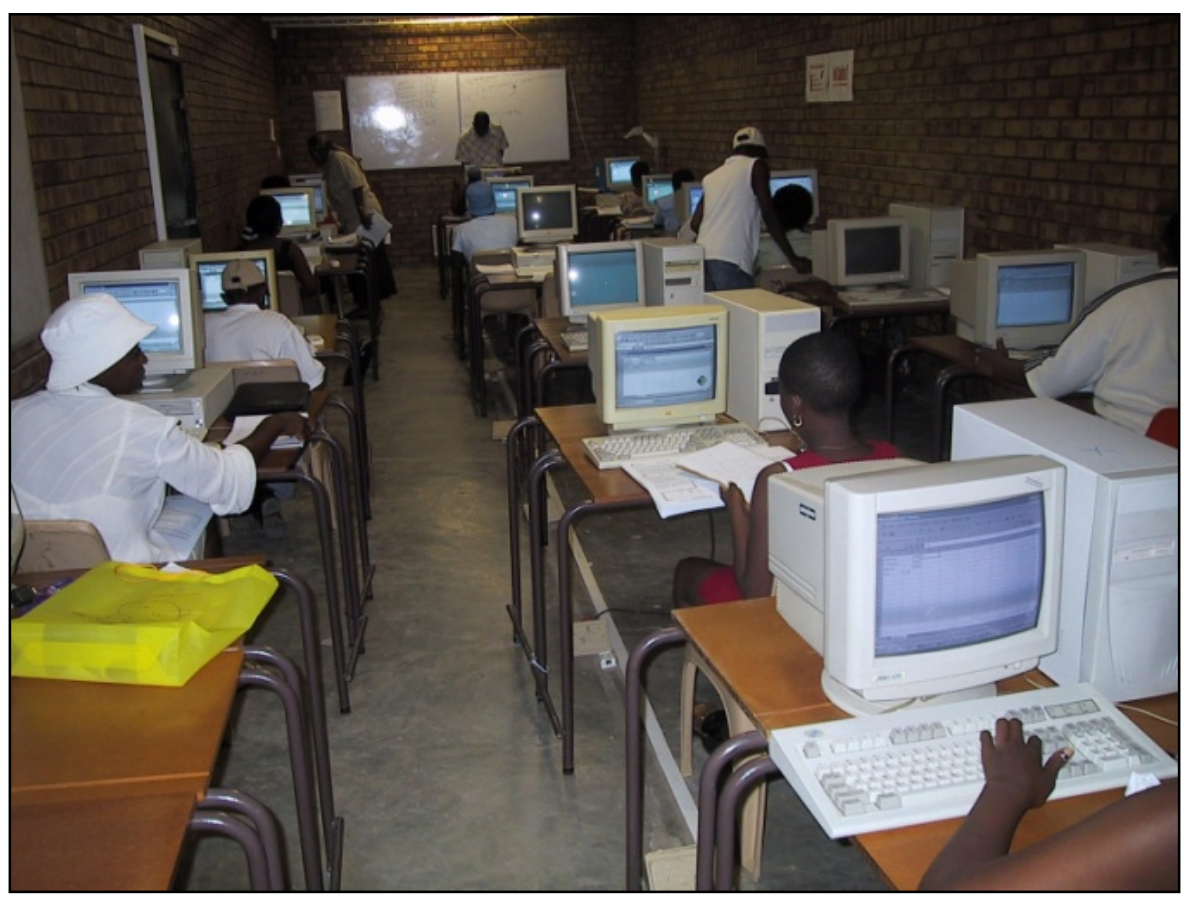

Source: Phahlamohlaka (2008) 
Exhibit 5: King Makhosonke of the Ndebele People and the SEIDET Board

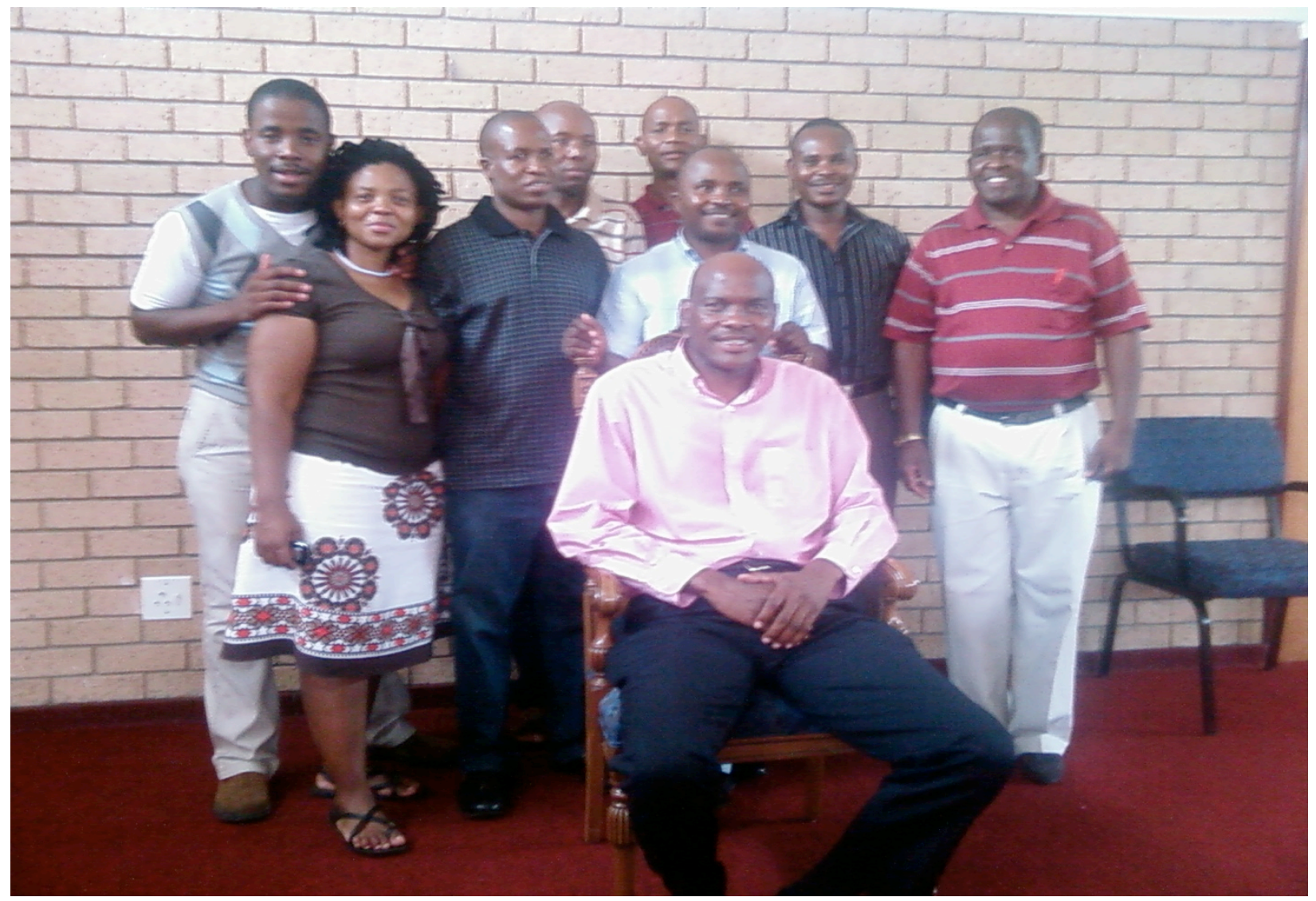

Source: Phahlamohlaka (2008) 